\title{
Infiltração clandestina: a questão da diferença no pensamento latino-americano
}

\section{Clandestine infiltration: the question of difference in latin american thought}

\author{
DOI: $10.21530 /$ ci.v13n2.2018.807
}

Lara Martim Rodrigues Selis ${ }^{1}$

\section{Resumo}

Este artigo constitui um esforço de leitura de autores que se engajaram na reativação das margens como espaço de enunciação intelectual na América Latina. Nesse sentido, desenha-se uma reflexão cuja curiosidade seminal se direciona sobre o lugar em que o escritor latinoamericano joga com os signos de outro escritor, o europeu. Buscando analisar como algumas escolas enfrentaram o silenciamento epistemológico da região, o presente trabalho retoma brevemente a literatura produzida pelas teorias da dependência, pelo grupo modernidade/ colonialidade e pelos intérpretes da antropofagia. A partir de tal base, argumenta-se pelo espaço de enunciação marginal reativada através de uma epistemologia capaz de estabelecer a diferença como valor crítico. Através dessas lentes, sugere-se que, em cada uma daquelas correntes, verificam-se diferentes visões e graus distintos de resistência diante da figura da Europa ou dos países centrais. Ao fim, configuram-se múltiplas modalidades de infiltração clandestina, mas que compartilham da preocupação com um lócus de fala periférica.

Palavras-chave: Pensamento Latino-americano; Pós-colonialismo; Teoria das Relações Internacionais.

\footnotetext{
Abstract:

This paper expresses a reading effort of the Latin American authors who have been engaged with the reactivation of the margins as a space of intellectual enunciation. In order to analyze how some schools faced the epistemological silencing of the region, the present work briefly

1 Possui graduação em Relações Internacionais pela Universidade Estadual Paulista "Júlio de Mesquita Filho" (2008) e mestrado em Relações Internacionais pela Universidade de Brasília (2011). Atualmente é doutoranda em Relações Internacionais pela Pontifícia Universidade Católica do Rio de Janeiro, e Professora Assistente na Universidade Federal de Uberlândia (UFU).

Artigo submetido em 22/05/2018 e aprovado em 30/08/2018.
} 
resumes the literature produced by dependency theories, by the modernity/coloniality group and by the interpreters of anthropophagy. From this base, it is argued that those traditions have reactivated the marginal enunciation through an epistemological establishment of 'difference' as a critical value. Through these lenses, it is suggested that we can find, in each of those schools of thought, different visions and degrees of resistance against the figure of "Europe" or of the "central" countries. At the end, multiple modalities of "clandestine infiltration" are configured, but all sharing the concern with a peripheral speech locus.

Keywords: Latin American Thought; Postcolonialism; International Relations Theory.

\section{Introdução}

“O outro existe, logo pensa”, provoca Viveiros de Castro, que continua, “e se esse que existe é outro, então seu pensamento é necessariamente outro que o meu. Quem sabe até deva concluir que, se penso, então também sou outro" (2008, p. 117). Nessa sequência lógica, vemos o autor jogar com a dedução de Descartes, que é então subvertida pela contra ontologia do perspectivismo ameríndio. Da liberação desse saber, antes subalternizado, Viveiros de Castro retira um significado distinto para um signo já habitual à imaginação moderna, qual seja, a alteridade. Assim, se para a cultura moderna, a existência de si implica a negação do outro, para a filosofia ameríndia acionada, a mesma existência só é possível pela afirmação da outridade.

Sob escopo ampliado, tais palavras de Viveiros de Castro traduzem um desafio mais geral apresentado por outros tantos autores que, cada qual à sua maneira, irrompem contra o solipsismo descartiano, a fim de propor o pensamento como potência de alteridade. Tal seria, por exemplo, o horizonte de resistência que perpassou diversas teorias do século XX, as quais, ainda hoje, engajam-se criticamente contra as estratégias de legitimação da diferença colonial ${ }^{2}$ praticadas $^{2}$ pelas estruturas de poder modernas/coloniais. Assim, já na metade do século XX, é possível identificar ondas de contestações que fluíam de todo o Terceiro Mundo, colocadas contra os discursos totalizantes renovados por signos como o “subdesenvolvimento".

2 Neste trabalho, toma-se o conceito de “diferença colonial” conforme exposto por Mignolo (2007, p. 37), que explica: trata-se de uma "classificação do planeta no imaginário colonial/moderno praticada pela colonialidade do poder, uma energia e um maquinário que transformam diferenças em valores”. Ou seja, a diferença colonial compõe o terreno de onde derivam matrizes de dominação, a exemplo do racismo e do ocidentalismo, que permeiam o imaginário do sistema mundial moderno, desde os conflitos imperiais até hoje. 
Em comum, autores da América Latina, África e Ásia problematizavam a posição geocultural hegemônica da Europa e de suas categorias analíticas. Por conseguinte, verifica-se a consolidação de esforços teóricos, cujo olhar, investido do propósito crítico, torna-se igualmente indissociável do fenômeno histórico da ciência moderna e de suas contradições. Sob esse horizonte, o presente artigo almeja mapear algumas das literaturas que buscaram enfrentar tal metafísica dualista da razão, estabelecendo como objetivo geral o intuito de compreender algumas das particularidades das respostas latino-americanas. Afinal, é possível pensar sobre (e contra) o sistema mundo moderno, desde uma posição exterior? Ou ainda, no contato entre centro e periferia, haveria um espaço para enunciação crítica, desde as margens?

No trajeto dessa revisão, o artigo se atenta às contribuições realizadas em diferentes domínios intelectuais do pensamento social latino-americano, buscando assim abordar três coletivos ${ }^{3}$ teóricos que ganham destaque a partir da segunda metade do século XX: as teorias da dependência; o grupo modernidade/ colonialidade e os intérpretes da antropofagia ${ }^{4}$. Certamente, não advogo o fato daquelas serem as únicas, ou mesmo as mais representativas correntes do pensamento social produzidos na América Latina. Tendo em vista a extensão histórica e teórica da produção intelectual da região, qualquer escolha implicaria limites que, embora metodologicamente impulsionados, não escapam ao domínio dos interesses de quem escreve ${ }^{5}$.

3 A escolha pela referência a "grupos" teóricos não se faz sem a ciência dos riscos implicados nesse tipo de taxonomia. Reconhece-se, portanto, que tais divisões coletivas jamais são inequívocas, e que um tratamento completo de suas particularidades internas, embora desejável, apresenta-se impraticável ao presente artigo. Por outro lado, a manutenção de tal recorte justifica-se pelo entendimento de que, ainda que precárias, tais caixas taxológicas traduzem movimentos históricos e sociais relevantes para a compreensão e localização da produção intelectual latino-americana. Assim, espera-se que a aplicação dessas identidades sirva ao exercício de uma espécie de sociologia do conhecimento que, somada à análise teórica, sustente um mapeamento satisfatório da temática analisada.

4 É importante pontuar que essa terceira referência, vinculada aos intérpretes da antropofagia, não traduz uma escola ou programa unificado de investigação teórica. Por outro lado, como explica Beatriz Azevedo (2016), as últimas décadas assistem a um revigoramento de autores que trazem novas luzes à obra oswaldiana, especialmente através da mobilização do tema da antropofagia como material interpretativo do Brasil e da América Latina. Nessa tendência, incluem-se nomes como Eduardo Viveiros de Castro, Luiz Costa Lima, Silviano Santigo, dentre outros.

5 Cabe aqui uma nota de ciência autoral sobre os limites desse recorte. Este que, ao selecionar os três programas supracitados, acaba por não tocar diretamente perspectivas e autores igualmente importantes - como José Carlos Mariátegui (Peru), Sergio Bangú (Argentina), Aldo Ferrer (Argentina), Florestan Fernandes (Brasil), Orlando Fals Borda (Colombia), Silvia Rivera Cusicanqui (Bolívia), René Zavaleta Mercado (Bolivia), dentre outros. 
Assim, frente à demanda por um olhar pormenorizado, julguei aqueles três grupos como fontes seminais da produção teórica latino-americana que busca romper com a subalternização epistemológica promovida no choque entre as culturas colonizadas e colonizadoras. Mirando o problema da diferença, argumento pela potencialidade específica do que considero ser os conceitos catalisadores daquelas propostas, quais sejam, respectivamente: a noção de dependência; os conceitos de colonialidade do poder e pensamento liminar; e, por fim, a ideia da antropofagia.

Em cada um desses conceitos, verificam-se rupturas específicas com a narrativa moderna. Dessa forma, se na primeira perspectiva vemos a concepção de um contato atravessado pela contradição dialética, inerente e vinculante, na segunda, a noção de "fronteira" engatilha o potencial da "exterioridade" como lócus da crítica à modernidade desde a diferença colonial. Alternativamente, outro caminho é aberto pela antropofagia, que confronta a razão dualista pela suposição do entre-lugar criado através do desejo antinarcísico pelo Outro. Ao fim, busca-se destacar como todas as três perspectivas se apropriam e ressignificam a diferença colonial, a fim de descolonizarem o quadro epistemológico hegemônico e abrirem espaço para a contribuição teórica das margens.

Em diálogo com o campo das Relações Internacionais, argumenta-se que tais correntes latino-americanas contribuem com a demanda por uma pluralização e descentramento científico da área, também anunciada por autores como Inayatullah e Blaney (2004), Spivak (1999), Tickner (2013), dentre outros. Segundo tais pensadores, a natureza (neo)imperial da disciplina, derivada de seu vínculo original com a filosofia europeia, torna imprescindível sua abertura teórica para a produção intelectual das regiões periféricas. Assim, nos três tópicos seguintes a essa introdução, apresenta-se um exercício de compreensão que, embora ainda incipiente, esforça-se para interpretar cada uma das três correntes, localizando-as no interior das tradições críticas latino-americanas.

\section{Movimento dos contrários: considerações sobre as teorias da dependência}

O desafio de se pensar as ciências sociais a partir da América Latina tem orientado diversas pesquisas na região, desde o início do século XX. Em grande medida, a extensão de tal provocação epistêmica deriva do argumento sobre uma 
espécie de dependência intelectual da teoria social latino-americana com relação aos marcos teóricos dos países centrais. Segundo essa lente, em sua origem, a produção intelectual na região realizou-se, sobretudo, mediante tentativas de adaptações das chaves do pensamento europeu para a realidade local, que então atravessava o período de construção e consolidação dos Estados (ANSALDI, 2015).

Assim, em parte, a correspondência entre a epistemologia moderna e as categorias analíticas do Estado-nação justificou a imposição daquela sobre os saberes nativos. No entanto, tal não implicou um vazio de contestações, de modo que, desde o século XIX, encontramos na literatura da região autores engajados criticamente com a utilidade dos modelos da tradição europeia frente às demandas locais por "cambio social” (ANSALDI, 2015, p. 19). Como explicam Bortoluci e Jansen (2013), o enfrentamento da subjugação cultural pelo Novo Mundo aparece nas pesquisas da região mesmo antes de um engajamento explícito com a linguagem do pós-colonialismo.

Embora não empreguem a linguagem explícita do "pós-colonialismo", muitos pesquisadores da América Latina desenvolveram análises e perspectivas que são, em muitos aspectos, compatíveis com aquelas avançadas por teóricos pós-coloniais [...]. Pensadores como José Martí, José Carlos Mariátegui, Gino Germani, Florestan Fernandes, Leopoldo Zea, e Edmundo O'Gorman, por exemplo, dedicaram a maior parte de suas carreiras ao desenvolvimento de interpretações históricas das sociedades Latino-americanas que se engajassem, de forma séria, no problema da “diferença colonial”, e que, ao mesmo tempo, servissem à crítica dos discursos populares e sociológicos sobre a modernidade frequentemente produzidos a partir da Europa. (BORTOLUCI; JANSEN, 2013, p. 204-207, tradução nossa) ${ }^{6}$

Portanto, como sugere a citação acima, na América Latina, a preocupação com o problema da diferença colonial antecedeu os processos de descolonização da segunda metade do século XX — notadamente ocorridos na África e na Índia. Isso porque, enquanto peça chave da primeira onda de expansão capitalista, a experiência colonial da América Latina remonta estruturas de dominação datadas desde o século XVI.

6 No original: "While not employing an explicit language of "postcolonialism” many scholars of Latin America have developed analyses and perspectives that are in many ways compatible with those advanced by postcolonial theorists [...]. Thinkers such as José Martí, José Carlos Mariátegui, Gino Germani, Florestan Fernandes, Leopoldo Zea, and Edmundo O'Gorman, for example, dedicated most of their careers to the development of comprehensive interpretations of the histories of Latin American societies that took very seriously the problem of "colonial difference" and that, at the same time, served to critique the popular and sociological discourses of modernity that had been developed with reference to Europe." 
Por conseguinte, com a maioria das independências já encerradas nas primeiras décadas do século XIX, a região latino-americana recebe a segunda onda de expansão capitalista, de caráter monopolista, de forma distinta do restante do globo. Assim, enquanto os continentes africano e asiático assistiam as neocolonizações imperialistas, a América Latina experimentava os primeiros projetos de modernização e urbanização pós-independência - também sob a égide das grandes potências. Nesse contexto, as discussões sobre o campo da economia e da política avançaram para o centro do debate social da região, que começa a desenhar suas lentes teóricas.

Como explicam Bortoluci e Jansen (2013), reconhecer as particularidades da história colonial e pós-colonial da região latino-americana é tarefa central para aqueles interessados em compreender a inserção específica do pensamento latino-americano no movimento crítico global - sobretudo aquele vinculado ao debate da dependência. Portanto, importante notar como a popularidade do enfoque na economia política é acentuada no pós Segunda Guerra, quando o direcionamento estratégico dos EUA eleva o tema do desenvolvimento econômico à condição de diretriz taxonômica internacional. No quadro de estruturação da agenda acadêmica, destaca-se, pois, o impacto das teorias da modernização, prevalentes nas décadas de 1930 e 1940, bem como da crítica cepalina - desenvolvida por autores como Raul Prebisch e Celso Furtado nos anos de 1950 e 1960.

Tais vertentes, no entanto, chegam problematizadas nas últimas décadas do século XX, quando a falência do projeto desenvolvimentista dá margem para uma renovação da crítica local. Conforme destacam Bortoluci e Jansen (2013, p. 207, tradução nossa), "nas décadas de 1960 e 1970, essas tradições intelectuais foram revigoradas por novos movimentos intelectuais, artísticos, e políticos latino-americanos - e pela era da descolonização em todo mundo - e se cristalizaram em uma série de importantes inovações teóricas” " . Assim, a ascensão do Terceiro Mundo como signo geopolítico, o vigor das experiências políticas socialistas do período e os processos de descolonização da África encontram eco na realidade latino-americana através da chamada "sociologia crítica" (HURTADO 2006 apud ANSALDI, 2015).

Dessa fase, emergem as teorias da dependência e as análises do sistemamundo, que configuram duas das respostas mais conhecidas da região aos

7 No original: "in the 1960 s and 1970s, these intellectual traditions were reinvigorated by new Latin American intellectual, artistic, and political movements - and by the era of decolonization around the world — and crystallized in a series of important theoretical innovations”. 
dilemas da modernidade. Naquelas correntes, a relevância da economia política no debate social latino-americano é acompanhada pela centralidade da filosofia (ou teoria da história) fundamentada na noção hegeliana-marxista da dialética. Como explica Osório (2009), a segunda metade do século XX assistiu a criação de uma espécie de "tradição latino-americana" orientada epistemologicamente para a transformação social. Sob essa abordagem, destacou-se o uso comum da dialética, à qual foram acrescidas categorias como "pobreza, opressão, dignidade, e a necessidade de libertação” 8 (OSÓRIO, 2009, p. 31, tradução nossa).

Tal direcionamento teórico sustentou a difusão do argumento sobre uma produção global da dominação e seus conceitos derivativos, como "dependência", "subimperialismo" e "colonialismo". Dessa forma, no mesmo período, enquanto as teorias inauguradas pelo grupo sul-asiático dos Estudos Subalternos dialogavam, em maior ou menor grau, com as contribuições pós-estruturais, chamando atenção para as dimensões discursivas e culturais do imperialismo, as teorias da dependência, por sua vez, amparavam-se em uma epistemologia estruturalista ou em leituras dialéticas da tese marxista da acumulação9 (BORTOLUCI; JANSEN, 2013; KAPOOR, 2002).

Sob esse horizonte, o forte diálogo com a epistemologia marxista realizado por autores como Ruy Mauro Marini, Theotônio dos Santos e Vânia Bambirra aciona uma leitura da diferença colonial segundo os termos da contradição dialética. Nela, o outro (a colônia/periferia) torna-se imagem antitética, ou espelho malgrado do par dominante, cuja estrutura de opressão é perpetrada por demandas normativas de superação. Edificadas sobre essa base, as vertentes marxistas da dependência, em especial, particularizam-se pela análise dos processos de integração capitalista, reconhecendo sua face política indissociável das dinâmicas produtivas globais. Em outras palavras, atentam-se para uma estrutura de poder responsável pela produção global da opressão, a partir da qual a condição de subdesenvolvimento dos países periféricos é lida como o produto negativo do desenvolvimento das economias capitalistas centrais (MARINI, 1973).

Dessa estrutura de dominação, consolida-se a noção de dependência que, importante notar, traduz um termo sinóptico, cujo conteúdo abarca um conjunto complexo de características (econômicas, sociais e políticas) das

8 No original: “poverty, oppression, dignity, and the need for liberation”.

9 Cabe reconhecer a complexidade da tradição teórica da dependência, em cujo interior encontram-se importantes variações, tal qual a vertente marxista - formada por Ruy Mauro Marini. Theotônio dos Santos etc. — e a vertente pluralista ou weberiana - representada por Fernando Henrique Cardoso e Enzo Faletto. 
sociedades periféricas (CAPORASO, 1978). Tais características, vinculadas ao subdesenvolvimento, constituem os próprios mecanismos da diferença colonial, produzida e aprofundada pela divisão global do trabalho. Nesse quadro, o termo desigualdade assume a condição de chave interpretativa daquela condição, constituindo uma leitura específica da diferença, em que se sobressaem os termos do desenvolvimento econômico e social.

Segundo Ansaldi (2015), as abordagens da dependência respondem de forma particular ao paradigma dualista da teoria da modernização, representando, assim, uma das principais contribuições latino-americanas ao campo da pesquisa social internacional. Divulgada inicialmente pela CEPAL, na década de 1940, a perspectiva da modernização experimentou uma posição de destaque entre as fontes interpretativas dos problemas socioeconômicos da região. Para tal abordagem teórica, promovida por autores como W. W. Rostow e William Arthur Lewis, o outro era lido por categorias analíticas dicotômicas, que naturalizava a diferença colonial, subalternizando sua cultura e conhecimentos.

Dessa forma, as sociedades latino-americanas foram tomadas como internamente distintas das sociedades avançadas, sendo, portanto, responsáveis pelo próprio subdesenvolvimento. Ou seja, nessa perspectiva, a diferença entre os Estados desenvolvidos e subdesenvolvidos refletia um atraso econômico e político dos últimos, cuja transformação adviria de uma postura mimética com relação às nações avançadas - que serviriam como modelo para um movimento civilizatório destinado ao progresso. Nos enunciados de tal teoria, revela-se, pois, o discurso que mobiliza a metafísica dualista (universal/particular etc.) centralizando suas "verdades" em detrimento de outras.

Tal binarismo do imaginário moderno desliza sobre uma consideração abstrata do tempo e espaço, relacionada à definição de um aqui e agora [dentro/hoje]; que se desdobra em uma construção de exterioridade igualmente fluída: um lá e um então [fora/antes]. Nesse sentido, ao confrontar a razão dualista do discurso moderno, expondo a produção da diferença como faceta negativa e intrínseca do projeto modernizador, as teorias da dependência irrompem também contra a narrativa temporal eurocêntrica. Utilizando a terminologia de Johannes Fabian, pode-se dizer que os teóricos da dependência auxiliaram no entendimento da "negação da coetaneidade", decodificada como instrumento central das políticas eurocêntricas da alteridade.

Assim, embora os teóricos da dependência não tenham se engajado diretamente nas discussões sobre a temporalização da diferença, sua crítica ao desenvolvimento 
colocou na agenda os problemas da narrativa civilizatória que sustenta as intervenções modernizantes nos chamados países subdesenvolvidos. Ademais, como aponta Mignolo (2003), a teoria da dependência marca um momento de autodescoberta epistemológica na América Latina, que então se percebe como parte de um sistema global de produção de conhecimento. Ou seja, ao demonstrar os limites teóricos e políticos do conhecimento eurocêntrico para o entendimento da realidade latino-americana, e chamarem atenção para o perigo do colonialismo interno praticado pelas elites locais, os teóricos da dependência atuam na crítica à hierarquia axiológica que atravessa a relação binária entre “a Europa e o Resto”.

Seguindo a leitura de Salazar Bondy (1968), a teoria da dependência agrega seu valor político na medida em que oferece à experiência do "Resto" uma igualdade epistemológica vis-à-vis as fontes europeias. Assim, para tal autor, o paradigma dessa escola serve de modelo para ruptura com a postura subserviente do conhecimento latino-americano com relação às culturas hegemônicas. Todavia, trata-se de uma intersecção de culturas pensada pela síntese dialética, cujo grau de sincretismo com as tradições europeias impulsiona muitas das denúncias póscoloniais sobre os limites da crítica dependentista à modernidade.

Por outro lado, cabe notar que se trata de uma apropriação do pensamento central reformulada a partir da diferença colonial no mundo moderno/capitalista. Portanto, o conceito do subimperialismo de Marini, por exemplo, relata uma conceitualização inspirada na tese marxista do imperialismo, porém transformada pela historicidade antitética da experiência periférica. Ademais, ainda em dissonância com a teoria do imperialismo de Lenin, a visão dependentista não percebe a produção global da opressão como uma etapa histórica do capitalismo, mas sim como condição ontológica estrutural do sistema. Tal reformulação advém do reconhecimento da experiência colonial, que então realoca os dilemas do capitalismo nos termos do sistema mundial. Ou seja, em diálogo com as próximas seções, expõe-se aqui uma forma importante, e particular, de ruptura com a epistemologia moderna realizada pelo retorno às experiências do outro colonizado.

\section{Habitar a fronteira: considerações sobre o grupo modernidade/colonialidade}

Como finalizou a seção anterior, a segunda metade do século XX contextualizou o direcionamento do pensamento crítico latino-americano para a ideia de um 
“sistema mundial” de opressão, tal qual desenvolvida por teóricos como Marini e Wallerstein. Os modelos do sistema mundial, fragmentados em periferias, semiperiferias e centros, experimentam fertilidade teórica nas décadas de 1960 e 1970, quando a força das leituras marxistas sustentava argumentos estruturais sobre as amarras produzidas, e posteriormente expandidas, pela divisão internacional do trabalho. Assim, conforme explica Go (2013), na metade do século XX, grande parte dos cientistas sociais que buscaram problematizar o papel da Europa e dos EUA em relação aos países periféricos o fizerem através das perspectivas do imperialismo e seu enfoque nas estruturas de dominação econômica.

Portanto, não raro, o tratamento das dimensões culturais daquela relação foram frequentemente abafadas através dessas lentes, que abriam pouca ou nenhuma margem para leituras do poder segundo suas dimensões racial, psicológica, cultural e de gênero. Alternativamente, já na década de 1970, o debate acadêmico do chamado Terceiro Mundo assiste à construção da "terceira onda de teorias póscoloniais"10. Tais abordagens, de forma geral, compartilhavam do diálogo com a crítica marxista do imperialismo, porém, ao mesmo tempo, buscavam superar seu vocabulário demasiado economicista e estruturalista. Com isso, miravam, dentre outras coisas, a ativação da agência como resultado de interações, isto é, apresentá-la enquanto elemento de relacionalidade, substituindo o debate colocado nos termos de “agente e estrutura” (GO, 2013).

Dessa forma, tal onda pós-colonial seguiu a base epistemológica voltada para a ruptura com a sociologia dualista das teorizações modernas. Ou seja, edificouse sobre a crítica à bifurcação analítica presente em imagens como: "Europa e o Resto”, “eu e outro”, “dentro e fora”, “doméstico e internacional”, dentre outras. Por outro lado, diferentes das leituras dialéticas da exploração capitalista, os autores do pós-colonialismo chamavam atenção para possíveis armadilhas implicadas na narrativa marxista, cujas categorias não escapavam ao discurso de uma história mundial homogênea - em que a heterogeneidade é continuamente negada na concepção da subjetividade.

Assim, da crítica ao marxismo, desponta o diálogo do pós-colonialismo com as estratégias teóricas da desconstrução. Embora não constitua uma filiação generalizante, a proximidade com as categorias oriundas do pós-estruturalismo europeu, vindos de autores como Foucault, Deleuze, Derrida e Lyotard, constitui

10 Para Darby e Paolini (1994), o pós-colonialismo desenvolveu-se através de 3 movimentos. No último, realizado na década de 1970, destaca-se o papel dos autores sul-asiáticos que promoviam um distanciamento dos aportes marxistas e uma aproximação das contribuições pós-estruturais e pós-modernas. 
uma característica marcante da produção intelectual de nomes como Spivak, Chakrabarty e Charttejee. Sob a liderança de Ranajit Guha, esses últimos autores compuseram, na década de 1970, o grupo de Estudos Subalternos, cujo objetivo era analisar criticamente a historiografia colonial da Índia produzida através de signos eurocêntricos, quer seja pelos ocidentais ou pelos próprios nacionalistas indianos (GROSFOGUEL, 2006, p. 20).

Na América Latina, o diálogo aberto com tal produção indiana foi relativamente tardio, ocorrendo apenas na última década do século XX, por meio dos intercâmbios acadêmicos realizados em ambiente universitário estadunidense. Desse contato, realizado na década de 1990, nasce o grupo latino-americano de Estudos Subalternos, que constitui a primeira inserção sistemática da região no debate teórico pós-colonial (BALLESTRIN, 2013). No entanto, tão logo o grupo latinoamericano começa a se desenvolver, sua sintonia inicial com as propostas sulasiáticas dá lugar às primeiras discordâncias.

Em grande medida, tal se deve à resistência dos autores latino-americanos à filiação com a epistemologia pós-moderna europeia, cuja perspectiva interna da modernidade produziria, no limite, uma crítica eurocêntrica ao eurocentrismo (GROSFOGUEL, 2006). Ademais, assumir o imaginário do pós-estruturalismo francês ou da teoria crítica de Frankfurt, que identificam o século XVIII ou o Iluminismo como fontes seminais da modernidade, significaria excluir a própria experiência colonial da América Latina como parte central daquele projeto. Portanto, desafiar as fronteiras cronológicas da modernidade surgiu como a própria condição de possibilidade do pensamento pós-colonial latino-americano.

Nesse raciocínio, Mignolo justifica a maior receptividade da crítica póscolonial latino-americana à metáfora do sistema-mundo, na medida em que essa situa o século XVI como data crucial da constituição das estruturas modernas de colonialidade. Assim, Mignolo (2003) abre o caminho para a separação entre as perspectivas latino-americanas e sul-asiáticas, argumentando pela não aplicabilidade das teses de Ranajit Guha, Gayatri Spivak e Homi Bhabha para a análise dos casos latino-americanos. Com base no reconhecimento das particularidades históricas da região, as atividades do grupo latino-americano de Estudos Subalternos são encerradas em 1998, dando fôlego para a inauguração de um novo movimento, o chamado giro decolonial, organizado em torno do grupo modernidade/colonialidade.

Segundo Ballestrin (2013, p. 97), a origem de tal coletivo remonta a uma série de encontros realizados em 1998 na Universidad Central de Venezuela, onde se 
reuniram "Edgardo Lander, Arturo Escobar, Walter Mignolo, Enrique Dussel, Aníbal Quijano e Fernando Coronil”. Em comum, tais autores apresentaram o interesse por "uma forma distinta de pensamento, um paradigma outro, a possibilidade mesma de falar sobre "mundos e conhecimentos de outra forma" 11 (ESCOBAR, 2003, p. 52, tradução nossa). Com isso, verifica-se o estabelecimento de uma identidade coletiva mais fluída, que não sustenta a concepção de uma escola teórica, mas sim de um "programa de investigação" no seu sentido mais livre.

Entrementes, diz-se que o grupo $\mathrm{M} / \mathrm{C}$ não reflete uma homogeneidade nas pesquisas, de modo que a pluralidade de suas fontes torna o próprio desenho de uma genealogia daquele pensamento um desafio. De todo modo, como explica Escobar (2003), no emaranhado de inspirações do programa modernidade/ colonialidade certamente pode-se destacar as seguintes influências:

A Teologia da Libertação dos anos sessenta e setenta; os debates na filosofia e ciência social latino-americana sobre noções como filosofia da libertação e uma ciência autônoma (por exemplo, Enrique Dussel, Rodolfo Kusch, Orlando Fals Borda, Pablo Gonzáles Casanova, Darcy Ribeiro); a teoria da dependência; os debates na América Latina sobre a modernidade e a pósmodernidade dos anos oitenta, seguidos pelas discussões sobre hibridismo na antropologia, comunicação e nos estudos culturais dos anos noventa; e, nos Estados Unidos, o grupo latino-americano de estudos subalternos ${ }^{12}$. (ESCOBAR, 2003, p. 53, tradução nossa)

Em síntese, o programa apresenta-se como uma colcha em que se costuram perspectivas distintas intelectual e geopoliticamente - porém unidas pelo desafio de abordar os dilemas epistemológicos através da diferença colonial. Por isso, a produção de seus membros se autodeclara habitante das fronteiras do sistema epistêmico, traduzindo, assim, seu objetivo de constituir "um pensamento outro" e "não um novo paradigma" - como teria sido o caso da teoria da dependência (ESCOBAR, 2003, p. 54).

11 No original: "una forma distinta de pensamiento, un paradigma otro, la posibilidad misma de hablar sobre 'mundos y conocimientos de otro modo".

12 No original: "la Teología de la Liberación desde los sesenta y setenta; los debates en la filosofía y ciencia social latinoamericana sobre nociones como filosofía de la liberación y una ciencia social autónoma (e.g., Enrique Dussel, Rodolfo Kusch, Orlando Fals Borda, Pablo Gonzáles Casanova, Darcy Ribeiro); la teoría de la dependencia; los debates en Latinoamérica sobre la modernidad y postmodernidad de los ochenta, seguidos por las discusiones sobre hibridez en antropología, comunicación y en los estudios culturales en los noventa; y, en los Estados Unidos, el grupo latinoamericano de estudios subalternos” 
Nesse sentido, Dussel, Quijano e Mignolo destacam-se dentre os principais autores munidos desse esforço. Aos olhos desses, a investigação do sistema moderno implica um retorno às suas origens espaciais e temporais, o que os leva a um enfrentamento radical da diferença colonial. Nesse trajeto, os autores citados comungam pontos chave no tratamento do sistema moderno/colonial, a exemplo do já mencionado entendimento da "conquista de América" como momento formativo do eurocentrismo. Através dessa assertiva, tais autores chamam atenção para a correlação entre colonialismo e capitalismo, que emerge como pilar da noção de “colonialidade do poder”.

Através desse conceito, desenvolvido por Quijano (2000), entende-se que os povos colonizados experimentam, mesmo após o período colonial, uma rede de relações conectadas de dominação (nos níveis de classe, raça, gênero e conhecimento), as quais foram estruturadas segundo o padrão de poder do capitalismo global e eurocêntrico. Dessa forma, verifica-se o diálogo com as teorias sobre o subdesenvolvimento, responsável pela não abstração da economia mundial como instrumento importante do poder moderno. Por outro lado, o autor soma a tal perspectiva a noção da subalternização do conhecimento e das culturas não europeias como mecanismo chave da estrutura de dominação moderno/colonial.

Como explica Mignolo (2003), a noção de “colonialidade do poder” de Quijano permite a passagem de um mundo moderno para um mundo moderno/ colonial. Com isso, o grupo $\mathrm{M} / \mathrm{C}$ visa confrontar o entendimento intra-europeu da modernidade - presente nas obras de autores como Habermas, Giddens, Lyotard, Kant, Hegel, escola de Frankfurt etc. (ESCOBAR, 2003). Nas palavras do autor,

Uma vez que a colonialidade do poder tenha sido introduzida na análise, a 'diferença colonial' torna-se visível, e as fraturas epistemológicas entre a crítica eurocêntrica do eurocentrismo distinguem-se da crítica ao eurocentrismo apoiada na diferença colonial - articulada como pós-colonialismo" (MIGNOLO, 2003, p. 66).

Assim, o esclarecimento e desnaturalização das diferenças coloniais compõem o artifício utilizado pelos autores do grupo $\mathrm{M} / \mathrm{C}$, a fim de edificar a crítica subalterna da modernidade. Na edificação desse saber local, os autores do grupo M/C apresentam enfoques e desenvolvimentos específicos. Como sintetiza Escobar, “algumas dessas diferenças são explicadas, em certa medida, pelos diferentes enquadramentos, ênfases e objetivos - economia política para Quijano, uma 
filosofia da libertação para Dussel, literatura e epistemologia para Mignolo" 13 (2003, p. 61, tradução nossa). Logo, enquanto Quijano observa de forma atenta o papel dos elementos raciais nas estruturas de controle de trabalho e de recursos na modernidade, Dussel, por sua vez, investiga a violência implicada nos processos de negação da alteridade daquele sistema. Já Mignolo demonstra interesse pelo âmbito em que a diferença colonial se torna subalternização epistêmica, avançando, pois, na noção do "pensamento liminar".

Nesse ponto, chama-se atenção para como cada um dos enfoques sugere um questionamento normativo em torno do dilema da exterioridade - afinal, é possível pensar sobre (e contra) o sistema mundo moderno, desde uma posição exterior? A noção filosófica de exterioridade, bastante utilizada pelo grupo, remonta às reflexões de Enrique Dussel quando operando sob a filosofia da libertação na década de 1970. Influenciado pela filosofia de Levinas, e sua noção de alteridade, Dussel (2008) substituiu o recorte marxista na luta de classe pelo olhar dedicado ao conceito do Outro. Assim, a ideia de exterioridade traduz tal outridade ainda não absorvida pelo sistema totalitário vigente. Ou seja, tal conceito implica a condição de não ser representado, e por isso também ainda não negado pela estrutura de poder capitalista, sexista ou racista.

Com essa categoria, Dussel (1995) desloca nosso olhar para os lugares excluídos pelo discurso moderno/colonial; isto é, aqueles esquecidos pelo regime regulatório. Note-se, no entanto, que, ao contrário do que se possa inferir, a categoria de externalidade não sugere uma ontologia absolutamente apartada do moderno, mas sim uma posição desprovida de participação dentro do sistema. O exterior, nesse caso, traduz a diferença produzida pelo discurso hegemônico. Por isso, a exterioridade surge como alternativa à ontologia eurocêntrica implicada no que Dussel (1995) considera ser uma crítica totalizante produzida pelo pensamento marxista ocidental. Através de tal categoria, o autor propõe uma noção de "libertação" que não demanda um movimento dialético, mas sim uma “transcendência interna”. Isto é, um momento positivo (ou analético) que se realiza fora da negação dialética, na medida em que aponta um lugar que ainda não foi negado pelo sistema, qual seja, a própria exterioridade.

Mignolo (2003) é um dos expoentes na releitura dessa filosofia de Dussel. Tomada como alteridade radical, a ideia de exterioridade permitiu a Mignolo

13 No original: “algunas de estas diferencias son explicadas en cierta medida por los diferentes encuadres, énfasis y metas - economía política para Quijano, una filosofía de la liberación para Dussel, literatura y epistemología para Mignolo”. 
propor a divisão teórica entre fronteiras internas e fronteiras externas do sistema moderno/colonial. Tal separação não segue os termos da divisão entre periferia e semiperiferia, ou seja, não são consideradas “entidades distintas, mas sim momentos dentro de um continuum de expansão colonial e nas mudanças das hegemonias imperiais” (MIGNOLO, 2003, p. 66).

Assim, enquanto as fronteiras internas traduzem os conflitos entre impérios que compartilham uma mesma cosmovisão, as fronteiras externas representam o choque entre as culturas imperiais e colonizadas, sendo, portanto, o lugar de viabilização da diferença colonial. Ao olhar para as contradições criadas nesse último espaço, Mignolo (2003) propõe resistir à própria diferença decodificada enquanto subalternização pelos impérios coloniais. Para isso, chama atenção para a subalternidade epistemológica através do já mencionado conceito do “pensamento liminar”.

Configurando a voz do subalterno, tal conceito aborda um saber construído a partir de um movimento duplo de absorção e deslocamento do conhecimento hegemônico. Não se trata, portanto, de um sincretismo, mas de um processo violento de luta travada contra uma longa estrutura colonial de subalternização do conhecimento e de legitimação da diferença colonial (MIGNOLO, 2003, p. 35). Dessa forma, Mignolo (2003) reflete criticamente sobre a hegemonia universalista da modernidade chamando atenção para uma diversidade de histórias locais produzidas no contato com o Outro. Tais perspectivas particulares tornam-se interessantes na medida em que refletem uma “dupla tradução”, isto é:

[Permitem] uma intersecção entre formas de pensamento incomensuráveis (na perspectiva da modernidade): o marxismo modificado pelas línguas e pela cosmologia ameríndia e a epistemologia ameríndia modificada pela linguagem da cosmologia marxista, num diálogo trans-epistemológico que está reescrevendo e encenando uma história de quinhentos anos de opressão (como no movimento "zapatista”). O que todas essas palavras chave têm em comum é seu rompimento de dicotomias, pelo fato de elas próprias constituírem uma dicotomia. Esta, em outras palavras, é a configuração-chave do pensamento liminar: pensar a partir de conceitos dicotômicos ao invés de organizar o mundo em dicotomias. (MIGNOLO, 2003, p. 126)

Portanto, ao operar um movimento de incorporação e reformulação, o pensamento liminar traduziria uma dupla crítica (ou dupla consciência), que se coloca na intersecção do "bárbaro” e do "civilizado”. A crítica a ambas as posições 
constituiria, nesses termos, condição sine qua non para a edificação de "um outro pensamento", que "não é mais concebível na dialética de Hegel, mas localizado na fronteira da colonialidade de poder no sistema mundial moderno" (MIGNOLO, 2003, p. 103). Verifica-se, assim, uma proposta epistemológica vinculada a uma espécie de releitura da transcendência interna de Dussel, visto que constitui uma ruptura produzida desde as margens externas do sistema mundial moderno. Em outras palavras, segundo essa abordagem, o espaço de enunciação crítica da América Latina parece surgir de um movimento positivo de afirmação da exterioridade apresentada como fonte do processo libertário.

\section{Digerir o Outro: considerações em torno da antropofagia}

A ideia da antropofagia se inscreveu no cenário crítico latino-americano por meio da obra do brasileiro Oswald de Andrade, datada dos anos de 1920. Através das linhas do Manifesto Antropofágico, Oswald desenha tal chave interpretativa com intuito de superar os impasses experimentados pelos estudos culturais no Brasil. Acreditava-se, à época, que o apego da narrativa brasileira aos polos idealista (vinculada ao purismo nacionalista) e pessimista (contaminado pelo etnocentrismo europeu) teria gestado leituras equivocadas sobre a relação da cultura local visà-vis a tradição europeia. Assim, da incapacidade daquelas posições em lerem as contradições e co-constituições da relação entre o Velho e Novo Mundo, emerge a motriz para a fórmula oswaldiana e seus intérpretes, que buscaram superá-la pelo reconhecimento do híbrido.

Como nos fala Viveiros de Castro, o anticolonialismo em voga na academia latino-americano contemporânea deve muito ao Manifesto Antropofágico que, a seu ver, "é decolonial muito avant la lettre" $(2016,14)$. Ainda sobre o anticolonialismo, tal autor pontua:

Tudo isso veio evidentemente da antropofagia oswaldiana, a reflexão metacultural mais original produzida na América Latina até hoje. A antropofagia foi a única contribuição realmente anti-colonialista que geramos, contribuição que anacronizou completa e antecipadamente o célebre clichê uspianomarxista sobre as "idéias fora do lugar". Ela jogava os índios para o futuro e para o ecúmeno; não era uma teoria do nacionalismo, da volta às raízes, do indianismo. Era e é uma teoria realmente revolucionária. (VIVEIROS DE CASTRO, 2006-2008, p. 168) 
Nesse sentido, nas entre-linhas do modernismo antropofágico, revela-se um antimodernismo de vanguarda, cujo debate acadêmico a ele contemporâneo não soube absorver. Em relato de Marília de Andrade, filha de Oswald, os últimos anos de vida de seu pai, na década de 1950, foram marcados pelo pessimismo de quem era assombrado pelo temor do esquecimento (AZEVEDO, 2016). Em parte, a falta de reconhecimento de suas ideias na metade do século deveu-se ao próprio distanciamento do autor das cadeiras acadêmicas. Ou seja, Oswald de Andrade, diferente dos intelectuais em voga no período, nunca configurou um “periférico profissional”, tendo sido rejeitado pelas instituições universitárias, como a USP.

No entanto, já no final da década de 1960, começa-se a desenhar uma mudança significativa desse cenário, quando então os círculos de arte cênica e os movimentos musicais elevam Oswald ao "patamar dos mitos" (AZEVEDO, 2016). Dentre suas ideias mais reeditadas, a antropofagia ganha destaque pela infiltração que tem realizado em outros domínios intelectuais, como a filosofia, antropologia e diversos campos da cultura. Segundo Azevedo (2016, p. 22), para além da digestão crítica realizada por estudiosos como Raul Bopp, Antônio Cândido e Augusto de Campos, vemos, na virada deste século, o surgimento de uma nova onda de epígonos.

Nas palavras da autora, "nos últimos anos, uma nova safra de reflexões, mais pontualmente centradas no tema da antropofagia, será desenvolvida por intelectuais como Eduardo Viveiros de Castro, Gonzalo Aguilar, Alexandre Nodari, Suely Rolnik, Eduardo Sterzi, Sérgio de Castro e outros” (AZEVEDO, 2016, p. 22). Tais autores seriam responsáveis pela nova inserção da antropofagia nos debates acadêmicos da antropologia, do direito e da narrativa histórica (AZEVEDO, 2016, p. 22). Ademais, outros domínios se beneficiam desse novo fôlego oswaldiano, tal qual demonstram as contribuições de Silviano Santiago e Luiz Costa Lima, relacionados à renovação da antropofagia na crítica literária.

Em todas as releituras, evidencia-se o valor da antropofagia como catalisador de uma ruptura radical com os papéis do jogo moderno da alteridade, de modo que, através dela, o inimigo reaparece como positividade transcendental. Trata-se, portanto, de uma contra ontologia, que inverte e cancela a prioridade do verbo ser - tipicamente protagonista das encenações teóricas modernas (VIVEIROS DE CASTRO, 2016). Nesses termos, a antropofagia desfaz o império solipsista do Eu dando lugar ao desejo antinarcísico pelo Outro. 
Comer o inimigo não como forma de "assimilá-lo”, torná-lo igual a Mim, ou de "negá-lo" para afirmar a substância identitária de um Eu, mas tampouco transformar-se nele como em um outro Eu, mimetizá-lo. Transformar-se, justo ao contrário, por meio dele, transformar-se em um eu Outro, autotransfigurarse com a ajuda do "contrário”. Não ver-se no outro, mas ver o outro em si. (VIVEIROS DE CASTRO, 2016, p. 15-16).

Ademais, no Manifesto de Oswald de Andrade, o uso alegórico da imagem antropofágica soma-se à aplicação de estratégias estilísticas, como a paródia e o absurdo que, juntas, encerram uma provocação profunda contra as hierarquias da imaginação moderna - tais como lógico e pré-lógico, civilizado e selvagem (AZEVEDO, 2016, p. 215-216). O conceito do “perspectivismo ameríndio”, proposto por Viveiros de Castro em conjunto com Tânia Stolze Lima, guarda semelhanças com o trajeto oswaldiano. Como esse, Viveiros de Castro busca encontrar no pensamento ameríndio um parceiro para a perturbação intelectual das dicotomias da modernidade.

A hipótese perspectivista relata que os "regimes ontológicos ameríndios divergem daqueles mais difundidos no Ocidente precisamente no que concerne às funções semióticas inversas atribuídas ao corpo e à alma”, subvertendo, assim, também os binários correlatos, como universal e particular, fato e valor, animalidade e humanidade (VIVEIROS DE CASTRO, 2015, p. 36-37). Dessa forma, a cosmologia ameríndia opera um escopo ampliado do atributo da "personitude", de modo que, a todos agentes humanos e não humanos, atribui-se o potencial ontológico de se revelarem ou se transformarem em pessoas. Logo, ser humano não seria uma questão de essência, mas sim de perspectiva, de ocupar um ponto de vista disponível a todo ser vivente.

Dessa assertiva deriva a suposição de que todo ser vivente pode ser pensado como sujeito, i.e, como enunciador de uma perspectiva. Nesse caso, a condição de sujeito não deriva de uma capacidade solipsista de pensamento, mas da condição de ser pensado por outrem como sujeito. Aqui, revela-se o valor central imputado à alteridade, que atua como conector entre as perspectivas do eu e do inimigo (SZTUTMAN, 2008). Portanto, para Viveiros de Castro (2008, p. 118), seria justamente essa habilidade do pensamento ameríndio em afirmar a "vida do outro como implicando um outro pensamento" que funda a "identidade profunda e radical entre antropologia e antropofagia”.

Assim, a diferença, traduzida na multiplicidade de pontos de vista, emerge como alternativa ao emblema umbilical moderno que, para afirmar o eu, precisa negar o 
outro. Trata-se, portanto, de uma contribuição singular para o campo da tradução intercultural. Afinal, ao expor as dificuldades de ler o outro pensamento senão através do próprio sistema cultural, o perspectivismo, assim como a antropofagia, alerta para a necessidade de um esforço de "pôr os 'nossos termos' em relações perigosas”, ou seja, expô-los a fim de forçar sua imaginação a supor o inaudível, e caminhar para a indisciplinariedade (VIVEIROS DE CASTRO, 2008, p. 122).

Na percepção de Viveiros de Castro (2005), as disciplinas acadêmicas atravessam um processo contemporâneo demarcado pela imaginação indisciplinada de seus objetos de estudo. Assim, vaticina o autor: o conhecimento deve se transmutar "não só por que o logos não é mais o que foi, mas porque o anthropos não será mais o que é”. Com esse termo, não se advoga uma desorganização intelectual, mas sim uma capacidade epistemológica de observar ordenamentos sociais cuja dinâmica rompe as fronteiras da imaginação política vigente.

Como se pode identificar até o momento, os dilemas da tradução (e da interação) intercultural, quando lidos pelas alegorias indígenas, quer seja a antropofagia, quer seja o perspectivismo, acabam implicando um vocabulário da resistência. Nas palavras de Lima (1991, p. 27), “a antropofagia, tanto no sentido literal como no metafórico, não recusa a existência do conflito, senão que implica a necessidade da luta”. Ou seja, na obra de Oswald de Andrade, a antropofagia materializa um traço de resistência primitiva que emana dos trópicos contra a doutrinação do colonizador. Tal seria o já mencionado canibalismo simbólico, cuja força reside na operação de uma transformação inerente do elemento digerido.

Como explica Lima (1991, p. 31), ao flertar com a psicanálise freudiana, a antropofagia envolve uma espécie de "transformação do tabu em totem, i.e, a metamorfose do símbolo excludente em includente”. Por essa abordagem, sustenta-se o argumento sobre uma internalização não passiva do Outro, em que os valores estrangeiros são absorvidos, porém reformulados e reanimados através do corpo nativo. Tais interpretações de Luiz Costa Lima compõem, portanto, outra importante fonte crítica da antropofagia. Diferente do enfoque antropológico de Viveiros de Castro, tal autor dedica-se ao campo da crítica literária, na qual, inclusive, apresenta uma leitura mais cautelosa do potencial contra-hegemônico da obra de Oswald de Andrade.

De forma geral, Lima (1991) indica uma preocupação com os riscos de reprodução eurocêntrica implicados no processo de digestão antropofágica. Afinal, porquanto transforme o Outro, a metamorfose não o faz sem antes preservar o elemento original. Logo, dos vínculos entre a antropofagia cultural e os valores 
ocidentais derivam os possíveis limites da crítica oswaldiana à modernidade. Ao apontar a incapacidade da proposta de canibalização realizar um solapamento radical da razão instrumental, Lima (1991) anuncia, a um só tempo, a importância e os limites da hipótese oswaldiana sobre a antropofagia cultural.

Por outro lado, ainda no campo dos estudos literários, verificam-se as discussões de Silviano Santiago (2000), que retomam a antropofagia como artifício robusto para a investigação do lugar em que o escritor latino-americano joga com os signos de outro escritor, o europeu. Desse substrato, Santiago (2000) infere a argumentação contrária a qualquer status de pureza ou de transmissão passiva entre dois códigos em contato. Com base na metáfora da antropofagia, tal autor atenta-se para o modo como o movimento de diferença colonial - em parte demarcado por imposições e assimilações - nos ofereceria outra transformação, a qual não opera no espaço da ação de um (colonizador) sobre outro (colonizado), mas sim no espaço de negociação da própria oposição.

Com isso, sugere-se que, naquele entre-lugar onde ocorre a digestão do outro, reside o espaço crítico a partir da qual podemos ler a produção intelectual da América Latina. Com tal proposta, Santiago (2000) denuncia a falência do modelo hermenêutico colonizador, contra o qual propõe um método capaz de restaurar o pensador latino-americano como parte do processo cognoscente. Em outras palavras, o autor confronta o que considera ser um modelo de completa submissão aos modelos culturais europeus, o qual, orientado para o estudo dos textos a partir de suas fontes ou influências teóricas, acaba por atribuir uma espécie de passividade neocolonial aos escritores do "Novo Mundo".

Nessa perspectiva, argumenta-se sobre uma política de leitura que demarque uma nova postura ética com relação ao Outro, confrontando seu apagamento sistemático na concepção do sujeito. Nesse movimento, Santiago (2000) parece pretender abrir espaço para a lógica enquanto propriedade não restrita à Europa, reconhecendo-a como elemento presente também em outros sistemas de conhecimento. Defende-se, pois, uma postura mais produtiva, segundo a qual aquele que lê um texto acaba também por produzi-lo, na medida em que desloca seu sentido original ao criar uma interpretação própria do mesmo. $\mathrm{Ou}$ seja, o enfoque nas aquisições e corrupções realizadas ao longo do movimento de assimilação de uma cultura por outra busca trazer o elemento do híbrido para o centro do debate da alteridade. Tal abordagem, aplicada à análise do contato entre o pensamento europeu e o latino-americano, sustenta o argumento sobre as transformações fundamentais que ocorrem no espaço desse encontro. 
A maior contribuição da América Latina para a cultura ocidental vem da destruição sistemática dos conceitos de unidade e de pureza: estes dois conceitos perdem o contorno exato de seu significado, perdem seu peso esmagador, seu sinal de superioridade cultural, à medida que o trabalho de contaminação dos latino-americanos se afirma, se mostra mais e mais eficaz. A América Latina institui seu lugar no mapa da civilização ocidental graças ao movimento de desvio da norma, ativo e destruidor, que transfigura os elementos feitos e imutáveis que os europeus exportavam para o Novo Mundo. (SANTIAGO, 2000, p. 6)

Sob esse horizonte, aponta-se o movimento de mutação do elemento original (europeu) pela mistura com o elemento teórico autóctone, como lugar de enunciação através do qual o pensamento latino-americano consegue resistir à cultura ocidental moderna. Ou seja, assumindo que o contato entre as culturas impossibilita um retorno à pureza, para ambos os lados, argumenta-se que, no jogo entre a assimilação e a expressão, os autores latino-americanos dinamizam uma espécie de infiltração clandestina do pensamento selvagem no substrato europeu. Desse ritual antropófago do pensamento subalterno, emergem conceituações de fronteira, as quais inauguram um lócus de fala periférica.

Em diálogo com o tópico anterior, a proposta da antropofagia, assim como a de Mignolo (2003), aponta para a retomada a pluralidade de cosmovisões como alternativa ao epistemocídio realizado pelas traduções modernas com relação ao pensamento do outro. Em ambos os caminhos, verifica-se uma rica base sobre a qual podemos edificar reflexões sobre a descolonização epistêmica nas RI.

\section{Considerações finais}

Este trabalho chamou atenção para como cada uma das três perspectivas apresentadas representa um esforço teórico particular preocupado em romper com as narrativas de uma realidade social asséptica, destituída das contradições e das opressões que atravessam a relação de alteridade. Ademais, em cada uma, verificamos diferentes visões e graus distintos de resistência diante da figura da Europa ou dos países centrais. Ao fim, configuram-se múltiplas modalidades de “infiltração clandestina”, visto que variam as respostas dadas para a relação entre as culturas centrais e periféricas.

Nas vertentes da dependência, tal ocorre pela exposição dos limites das teorias da modernização para a realidade local, que se realiza através da revelação da 
diferença colonial enquanto choque de contradições. Pelas lentes dialéticas, a noção de contradição implica uma tendência simultânea à unidade e à oposição. Ou seja, traduz fenômenos que se excluem, mas cuja existência depende da própria interação. Por isso, a síntese não constitui uma negação absoluta dos termos, mas uma superação que, embora inaugure novo elemento, conserva em si parte da contradição anterior. Paralelamente, para os teóricos da dependência, as condições econômicas criadas pelo capitalismo global contribuíram para que o potencial de enunciação periférico, bem como a revolução socialista, emergissem de mesma fonte, qual seja: a síntese dialética.

Já o conceito do pensamento liminar de Mignolo mostra-se crítico a tal proposta de superação dialética, dado ao vínculo com um movimento histórico linear. Assim, a noção de "fronteira" confronta o relato retilíneo do universalismo moderno por meio do reconhecimento de diferentes abordagens da história presentes nos conhecimentos locais. Nessa perspectiva, a etapa mais radical da globalização abre a possibilidade de teorizar desde a margem, considerando a liminaridade realizada pela "dupla crítica” (ou dupla consciência). Através desta, a teorização sobre e a partir da margem não emerge como oposição ao pensamento central, ou mesmo sincretismo, mas como "deslocamento e ruptura”(MIGNOLO, 2003, p. 415).

Pelas lentes da antropofagia, outros caminhos são dados ao desafio de restaurar o outro na posição de sujeito cognoscente. No perspectivismo ameríndio de Viveiros de Castro, como citado, ou na leitura de Santiago, verifica-se alusão comum à metáfora antropofágica de Oswald de Andrade, segundo a qual a falsa obediência de assimilação teórica pelos sujeitos latino-americanos aponta um espaço de resistência no encontro desses com o pensamento europeu. Ou seja, através da tradução digressora dos conceitos "civilizados" pelos latino-americanos, emerge um processo de digestão dos imperativos modernos. Com isso, realiza-se a infiltração das experiências e falas subalternas na imaginação ocidental.

Ao fim, à luz das leituras mapeadas nessa revisão, podemos problematizar a capacidade da nossa disciplina em abrir-se para novos loci de enunciação. Nesse quadro, argumenta-se que o estudo das críticas latino-americanas se destaca pela capacidade de introduzir na agenda da disciplina o debate sobre a emancipação social enquanto projeto indissociável da proposição de epistemologias e conceitos mais compatíveis com a descolonização do pensamento. 


\section{Referências}

ANSALDI, Waldo. Entre perplejidades y angustias. Notas para pensar lascienciassociales latinoamericana.IN: Yamandú Acosta et.al (Coord). América Latina piensa en América Latina. 1a ed. Ciudad Autónoma de Buenos Aires: CLACSO, 2015.

AZEVEDO, Beatriz. Antropofagia: Palimpsesto Selvagem. São Paulo: Cosac Naify, 2016. BALlESTRIN, Luciana. América Latina e o giro decolonial. Rev. Bras. Ciênc. Polít. 2013, no. 11, p. 89-117.

BORTOLUCI, José H.; JANSEN, Robert S. Toward a Postcolonial Sociology: The view from Latin America. IN: GO, Julian (ed). Postcolonial Sociology: Political Power and Social Theory, v. 24, 2013, p. 199-229.

CAPORASO, James A. Dependence, dependency and power in the global system: a structural and behavioural analysis, International Organization, vol. 32, n. 1, 1978, p. 13-43.

DARBY, Phillip; PAOLINI, A.J. Bridging International Relations and Postcolonialism. Alternatives: Global, Local, Political. v. 19, 1994, p. 371-397.

DUSSEL, Enrique.The Invention of The Americas. Trans. Michael Barber. New York: Continuum, 1995.

DUSSEL, Enrique. Twenty Theses on Politics. Translated by George Ciccariello-Maher. Duke University Press, 2008.

ESCOBAR, Arturo. Mundos y Conocimientos de otro modo: El programa de investigación de modernidad/colonialidad latinoamericano. Tabula Rasa. Bogotá - Colombia, no. 1, 2003, p. 51-86.

FIGUEIREDO, Vera F. Antropofagia: uma releitura do paradigma da razão moderna. In: RUFFINELLI, Jorge; ROCHA, João Cezar de Castro. Antropofagia Hoje? Oswald de Andrade em Cena. São Paulo: Editora Realizações, 2011.

GO, JULIAN. Introduction: Entangling Postcoloniality and Sociological Thought. In:

(ed). Postcolonial Sociology: Political Power and Social Theory., v. 24, 2013, p. 3-31. GROSFOGUEL, Ramón. La Descolonizacíon de la Economía Política y los estudios Postcoloniales: Transmodernidad, pensamiento fronterizo y colonialidad global. Tabula Rasa. Bogotá - Colombia, No. 4, 2006, p. 17-48.

INAYATULLAH, Naeem; BLANEY, David. International Relations and the Problem of Difference. New York: Routlege, 2004.

KAPOOR, Ilan. Capitalism, Culture, Agency: Dependency versus Postcolonial Theory. Third World Quarterly, Vol. 23, N. 4, p. 647-664, 2002.

LIMA, Luiz Costa. Antropofagia e Controle do Imaginário. In: Pensando nos trópicos (Dispersa Demanda II). Rio de Janeiro: Rocco, 1991, p. 26-39. 
MARINI, Ruy Mauro. Dialéctica de ladependencia. México D.F.: Ediciones Era, 1973. MIGNOLO, Walter D. Histórias Locais/ Projetos Globais: colonialidade, saberes subalternos e pensamento liminar. Trad. Solange Ribeiro de Oliveira. Belo Horizonte: Editora UFMG, 2003.

MIGNOLO, Walter D. Desobediência epistêmica: a opção descolonial e o significado de identidade em política. Trad Ângela Lopes Norte. Revista Gragoatá, n. 22, 2007.

OSORIO, Jorge Mario Flores. Praxis and Liberation in the Context of Latin American Theory. In: MONTERO, M; SONN, C.C. (eds.). Psychology of Liberation: Theory and Applications. New York: Springer Science + Business Media, 2009.

QUIJANO, Anibal. Coloniality of Power, Eurocentrism, and Latin America. Nepantla: Views from South, Duke University Press, v. 1, issue, 3, 2000, p. 533-580.

SALAZAR BONDY, Augusto. ¿Existe una filosofía de nuestra América? México: siglo xxi editore, 1968.

SANTIAGO, Silviano. Uma literatura nos trópicos: ensaios sobre dependência cultural. Rio de Janeiro: Rocco, 2000.

SPIVAK, Gayatri. A Critique of Postcolonial Reason: Towards a History of the Vanishing Present. Harvard UP, 1999.

SZTUTMAN, Renato. Apresentação. In: (Org). Encontros: Eduardo Viveiros de Castro. Rio de Janeiro: Azougue Editorial, 2008.

TICKNER, Arlene B. Core, periphery and (neo)imperialist International Relations. European Journal of International Relations, v.19, n.3, 2013, p. 627-646.

VIVEIROS DE CASTRO, Eduardo. Antropologia e imaginação da indisciplinaridade. Conferência proferida na UFMG, 2005. Disponível no link: < https://www.youtube. $\mathrm{com} /$ watch? $\mathrm{v}=$ rylykrRVqYk $>$.

VIVEIROS DE CASTRO, Eduardo. “Entrevista”. In: COHN, Sergio; REZENDE, Renato; CESARINO, Pedro. Azougue - edição especial, 2006-2008.

VIVEIROS DE CASTRO, Eduardo. O perspectivismo é a retomada da antropofagia oswaldiana em novos termos. In: SZTUTMAN, Renato (Org). Encontros: Eduardo Viveiros de Castro. Rio de Janeiro: Azougue Editorial, 2008.

VIVEIROS DE CASTRO, Eduardo. Metafísicas canibais: elementos para uma antropologia pós-estrutural.São Paulo: Casac Naify, 2015.

VIVEIROS DE CASTRO, Eduardo. Prefácio. In: AZEVEDO, Beatriz. Antropofagia: Palimpsesto Selvagem. São Paulo: Cosac Naify, 2016. 